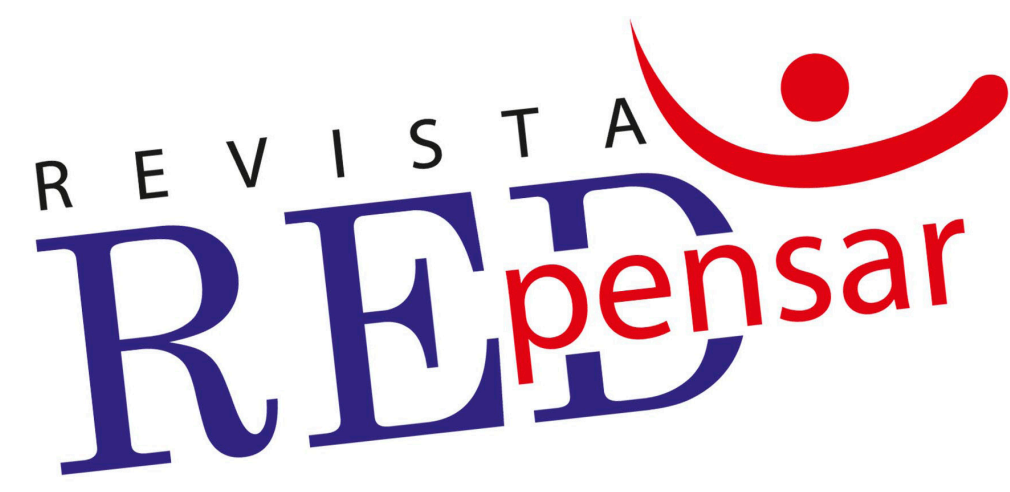

\title{
Memoria colectiva e identidades en El Triunfo
}

\section{Jose Pablo Hernández Gonzálezy Dylanna Rodríguez. Muñoz.}

Revista REDpensar, volumen 6, número 2, Julio-Diciembre 2017 ISSNe: 2215-5384

REDpensando en la Investigación 1 Recibido: 01 de octubre de 2018 Aceptado: 03 de diciembre de 2018

\section{(ㄷ)(1)(2)}




\title{
Memoria colectiva e identidades en El Triunfo
}

\section{Collective memory and identities in El Triunfo}

\author{
Jose Pablo Hernández González. \\ Dylanna Rodriguez. Muñoz ${ }^{2}$
}

\section{Resumen}

El presente artículo, se deriva de una investigación desarrollada en el marco de un Trabajo Final de Graduación, realizada de manera interdisciplinaria entre la Psicología y la Sociología, para optar por el grado de licenciatura, en la Universidad de Costa Rica, en la cual se estudió este proceso de recuperación de tierra entre los años 2011 y 2016. El escrito contiene el apartado del resultado de análisis, producto de los procesos de recuperación de la memoria colectiva y de las configuraciones indentitarias, desarrolladas en El Triunfo durante el periodo de tiempo estudiado. Además, se discuten las valoraciones respecto a la importancia de recuperar la memoria, donde el futuro tiene un lugar central, así como, las formas de identificación que han operado, siendo la tierra uno de los significantes de mayor peso, en relación con el modo de vida campesino. Finalmente una de las principales conclusiones que se presentan en este artículo es sobre la importancia de la recuperación de la tierra como sentido de pertenencia para la cultura campesina y la reivindicación de la agricultura familiar.

Palabras Clave: CAMPESINADO, RECUPERACIÓN, MEMORIA, IDENTIDADES, TIERRA.

\section{Abstract}

The following article is the result of a final research project in order to obtain a degree in Universidad de Costa Rica. It is characterized by its interdisciplinary approach between Psychology and Sociology. The analysis of land reclamation processes in El Triunfo allows to present the result of collective memory recovery and identity configurations developed during the study period between 2011 and 2016. Appraisements towards the importance of memory recovery are argued; future is spotlighted, as well as, the identity forms displayed, being the land a very important significant in relation with the peasant way of living. The writing contains the section of the result of analysis, product of the processes of recovery of the collective memory and of the identity configurations, developed in El Triunfo during the period of time studied. In addition, valuations are discussed regarding the importance of recovering memory, where the future has a central place, as well as the forms of identification that have operated, with land being one of the most significant signifiers, in relation to the way of peasant life. Finally, one of the main conclusions presented in this article is about the importance of recovering the land as a sense of belonging to the peasant culture and the claim of family farming.

Keywords: PEASANTRY, RECOVERY, MEMORY, IDENTITIES, LAND.

"Lo que más me gusta de vivir aqui es vivir lo pacifico y natural que se vive aquí, lo natural que uno disfruta, un ambiente fresco y libre, es algo que lo llena a uno y lo contenta" Julián, El Triunfo

\footnotetext{
1. Licenciado en Psicología. Costarricense. Universidad de Costa Rica. Estudiante de la Maestría Profesional en Psicología Comunitaria, Universidad de Costa Rica. Correo electrónico: jose.ucr@,live.com

2. Licenciada en Sociología. Costarricense. Universidad de Costa Rica. Docente, Vicerrectoría de Acción Social, Universidad de Costa Rica. Correo electrónico:dylirm@gmail.com
} 


\section{Presentación}

Este artículo es resultado de un proceso de investigación llevado a cabo de manera interdisciplinaria entre la Psicología y la Sociología, en el marco del Trabajo Final de Graduación del autor y la autora para optar por el grado de licenciatura, en la Universidad de Costa Rica. Este estudio se realizó en conjunto con la comunidad campesina El Triunfo, abarcando el periodo comprendido entre los años 2011 y 2016, como una forma de aportar desde la academia al conocimiento del contexto que viven los sectores campesinos en Costa Rica, a través de sus procesos de organización para la reivindicación de sus derechos.

El Triunfo se ubica en el cantón de Los Chiles, en la provincia de Alajuela, a pocos kilómetros de la frontera con Nicaragua. Se trata de una comunidad que inició un proceso de recuperación de tierra el día 8 de abril del 2011 y que se mantiene en el presente, experimentando al menos seis desalojos violentos por parte de la Fuerza Pública y agentes de seguridad privada, contratados por el arrendatario de la finca.

La finca en la que se encuentra esta comunidad es de una extensión aproximada de 360 hectáreas y era conocida anteriormente como Naranjales Holandeses, la cual al momento del inicio de la recuperación de tierra estaba arrendada por un empresario agropecuario local. Este terreno en la actualidad se encuentra en un proceso de expropiación por parte del Instituto de Desarrollo Rural (Inder), como producto de la organización de al menos 150 familias campesinas, la gran mayoría de origen nicaragüense y en condición de pobreza.

Se considera valioso la publicación de este estudio, en tanto contribuye a la producción de conocimiento alrededor de los procesos de lucha contra la pobreza y la exclusión, visibiliza acciones asociadas a la ecología y el cuido de la vida, así como, la promoción de la comunicación, la cultura y la diversidad, apelando a un reconocimiento legítimo del Otro, partiendo desde un compromiso ético con los sectores excluidos.

De este modo, las recuperaciones de tierra implican múltiples dimensiones de análisis, por ejemplo, contexto socioeconómico, historización de las políticas públicas relacionadas con el ámbito rural, formas de producción y comercialización, organización comunitaria, lugar de la mujer en la lucha por la tierra, formas de violencia estatal, entre otros. No obstante, el presente texto se centra en los procesos de recuperación de la memoria colectiva involucrados en la historia de lucha de El Triunfo y las formas de identificación, imagen social y pertenencia que se han construido (Avanza y Laferté, 2017).

Para recopilar la información que se presenta, se partió desde las propuestas metodológica de la Investigación Acción Participativa (IAP) y pedagógica de la Educación Popular. De manera que se realizaron entrevistas en profundidad con personas clave de la comunidad, talleres participativos y revisión de fuentes secundarias tanto escritas como audiovisuales.

Ahora bien, se entiende por comunidad un ente dinámico que, al igual que las personas que la conforman, está siempre en un proceso inacabado de reconstrucción, pero que representa un punto de encuentro material y simbólico que aglutina la noción de nosotros. Coincidiendo con Montero (2004), cuando apunta que "no nos referimos a grupos homogéneos, pero sí a grupos compuestos por individuos, que comparten conocimientos, sentimientos, necesidades, deseos, proyectos" (p. 201).

La identificación como nicaragüenses, y por lo tanto en este caso la imagen de migrantes, así como sentido de pertenencia ligado al campo, son elementos fundamentales de la constitución de la subjetividad de estos sujetos, quienes además han tenido que lidiar con imágenes sociales producidas de discursos hostiles que los han nombrado como "precaristas", "vividores", "roba tierra" y "terroristas". En este sentido, también entran en juego otro tipo de calificativos tanto de individuos y organizaciones 
solidarias, como de las mismas familias al autonombrarse: "campesinas", "luchadoras", "valientes"; pero también, "pobres".

Lo anterior, en gran medida se ha expresado para estas familias en una posibilidad de lucha y de reivindicación política frente a otros, ya que, la contingencia de ciertas condiciones particulares al proceso de construcción de esta comunidad, asociadas con identificarse como sujetos privados de derechos, ha permitido el organizarse para realizar sus exigencias al Estado y posicionarse a su vez frente a los otros que intentan deslegitimar su lucha.

Estos procesos de identificación por supuesto no son monolíticos, sino que, por el contrario sufren transformaciones y retornos, un constante devenir que se sitúa en un contexto especifico. En este sentido, se comparte la propuesta de Avanza y Laferté (2017) cuando señalan que:

En el debate científico, el punto no es tanto estudiar las identidades construidas para desnaturalizarlas, sino más bien cuestionar las diversas fuerzas restrictivas y de institucionalización de las estructuras sociales que llevan las múltiples identificaciones, imágenes sociales y pertenencias, y que entran en disputa en este juego perpetuo de corte categorial e imaginario del mundo social. (p. 207)

Dicho lo anterior, se analiza, en primer lugar, la relación comunitaria entre la memoria colectiva y el proceso de recuperación de tierra, y de segundo lugar, la manera en que este se ha relacionado con las identidades construidas en la comunidad.

\section{Recuperación de la memoria colectiva y de la tierra}

El proceso de recuperar la tierra abrió en estas familias una reconstrucción como sujetos, teniendo en cuenta que ocurre con particularidades propias de cada individuo, pero que no escapa de una historia de vida común para un gran colectivo, que dio inicio desde las reuniones organizativas que antecedieron al primer ingreso a la finca el 8 de abril del 2011.

Además, para un gran conjunto de familias recuperantes sus biografías se unen en un pasado común, la mayoría de las veces marcado por la guerra, el despojo, la exclusión, la migración, la explotación y el dolor. A la vez que, han estado presentes la fuerza y el ánimo por mejorar sus condiciones de vida a pesar de las dificultades, en la búsqueda de un mejor futuro.

Retomando a Jelin (2014), los pasados comunes de estas familias se ven expresados en gran medida como memorias del sufrimiento, las cuales vale la pena recuperar en función de la importancia que se les otorga a nivel familiar y comunitario, con el fin de ser útiles para cuestionar críticamente y de manera propositiva la institucionalidad democrática.

Resulta interesante que, en el caso de El Triunfo durante las actividades grupales se preguntó a las y los participantes si consideraban importante recuperar la memoria colectiva sobre su lucha, la respuesta fue una afirmación contundente. En el siguiente cuadro (cuadro 1), se presentan las principales motivaciones que se argumentan en favor de mantener viva la memoria de su comunidad. 


\section{CUADRO 1. \\ ¿Por qué recuperar la memoria colectiva de la lucha?}

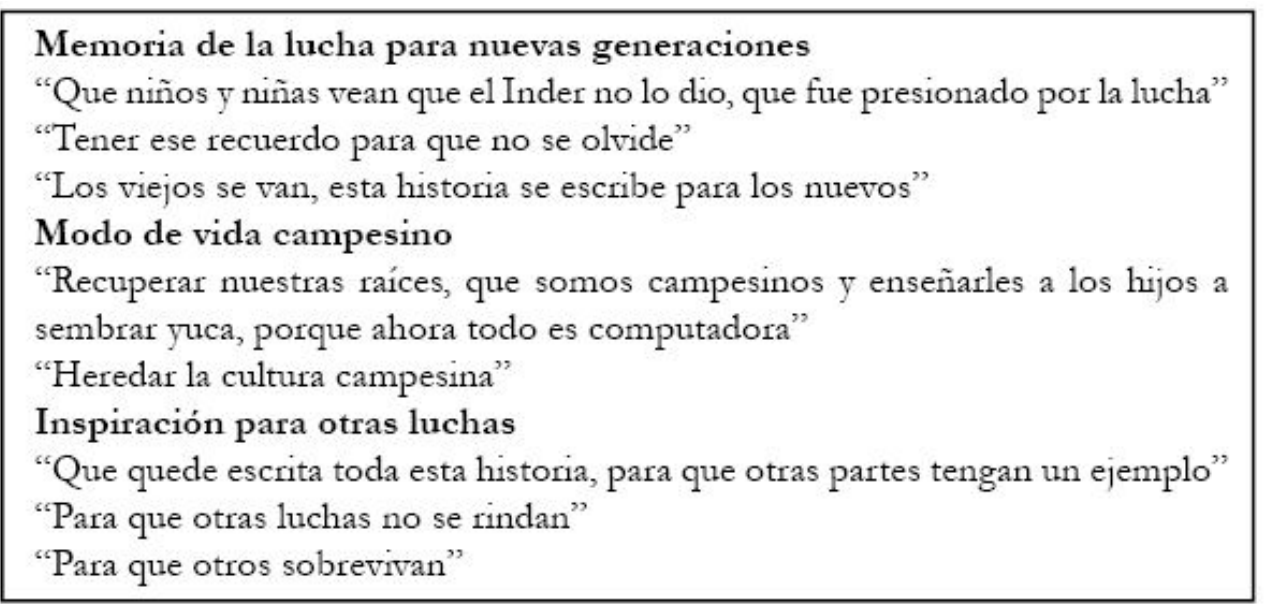

Fuente: Elaboración propia, a partir de actividades grupales, Agosto 2014.

Como se observa, la recuperación de la memoria tiene diversos objetivos, que no se limitan únicamente al registro de los episodios que articulan la lucha para ordenar su historia de manera cronológica. Se trata en cambio de, construir una conexión de sentidos (Calveiro, 2006) entre pasado y presente, para recuperar el sentido que este proceso ha tenido para sus protagonistas, sus significados en el presente y en perspectiva de su futuro. Esto por medio del ejercicio colectivo de recordar, para configurar una memoria común dinamizada por la interrelación entre las vivencias particulares que la componen.

Entre las razones que argumentan las familias de El Triunfo, a favor de recuperar la memoria colectiva de su lucha, se identifican dos elementos centrales. Por un lado, se encuentra el registro de la memoria para las nuevas generaciones, en el sentido de reivindicar la historia de la conformación de la comunidad como parte un proceso de lucha y no como un producto del azar o de políticas públicas exclusivamente. Por el otro lado, contribuir a mantener lo que nombran como la vida campesina y ser inspiración para otras resistencias similares.

Conservar la identificación con esta imagen campesina, involucra para las familias recuperantes identificarse como parte de una cultura que está bajo amenaza. Ahora bien, el riesgo que observan no es el de perder una identidad en sí misma, sino una serie de prácticas, conocimientos y valores que consideran útiles y que brindan sentido en ese contexto de reivindicación de derechos, donde el sentido de pertenencia tiene una estrecha relación con la tierra.

Inspirar otras luchas es el tercer objetivo que se identificó como valioso al recuperar la memoria de su proceso de resistencia, reconociendo la necesidad de continuar ganando espacios ante el actual modelo de desarrollo económico excluyente; lo cual, evidencia que la comunidad no se piensa de manera aislada, por el contrario, tiene la esperanza de que resistencias similares se multipliquen, al considerar que en tanto las familias sin tierra se organicen para la reivindicación de derechos, generarán músculo social para conseguir la satisfacción de sus necesidades y la solución a sus problemas.

Las familias recuperantes esperan que la memoria sobre su lucha colabore en el sostenimiento de la moral de otras organizaciones campesinas que se enfrenten a condiciones adversas, como la represión, la incertidumbre, la persecución, la exclusión socioeconómica, entre otras. Lo que evidencia una identificación con otros que no necesariamente se conocen pero de quienes se 
reconoce que existen, compartiendo biografías, cotidianidades y esperanzas similares, al tener como elemento generador de pertenencia la necesidad común de acceder a tierra.

De acuerdo a lo anterior, se destaca el papel que juega la recuperación de esta memoria de lucha como herramienta útil para la resistencia contra las formas de dominación y para poner en evidencia la capacidad que tienen los sectores excluidos de la sociedad, para reconstruirse como sujetos políticos y actuar como protagonistas de su propia historia (Cordero, 1998).

En esa dirección, una vez finalizado el proceso de actividades grupales para recuperar la memoria colectiva, se hizo una actividad de cierre donde las personas participantes, reconocieron otro elemento fundamental del ejercicio colectivo de conectar el pasado con el presente, en relación con la organización comunitaria.

-Esto sí es para bien, sirvió de mucho para nosotros y para mí recordar todo lo vivido en esta lucha, momentos bonitos y momentos feos. Nos sirvió para compartir, aprender y escuchar la opinión de los demás y así agarrar más fuerza para seguir luchando y llevar esto hasta el final-. (Dilma/mujer adulta/nicaragüense/Junio 2015)

Este relato pertenece a una de las principales lideresas comunitarias, el mismo da cuenta de que el proceso de recuperar la memoria es en sí mismo un elemento que forma parte de la lucha. Ya que la historia de la comunidad continúa su construcción integrando los aprendizajes que surgen del proceso de recordar, que se hace colectivo precisamente en el encuentro para compartir, escuchar y aprender mutuamente en el grupo.

En sintonía con lo descrito anteriormente, Rebelde también valoró su experiencia en esta dirección:

-Todas las actividades estaban respecto a los campesinos, para adelantar y recordar la lucha, el trabajo que se está haciendo por la lucha de la tierra. Luchando por el futuro de mañana. Aprender de estar aquí luchando y esperar algún día salir adelante-. (Hombre adulto/nicaragüense/Junio 2015).

En este fragmento, se evidencia como la recuperación de la memoria colectiva no consiste en una nostalgia o idealización del pasado, sino en atravesar el pasado, el presente y el futuro, creando conexiones entre los tres tiempos adelantar y recordar la lucha. El trabajo que se está haciendo por la lucha de la tierra. Lo que la posiciona como un proceso que genera aprendizajes desde la propia experiencia, impulsados por la esperanza de mejorar sus condiciones de vida.

Como se observa, en El Triunfo la relación entre la memoria colectiva y el proceso de recuperación de tierra se ha expresado en términos de construcciones de sentido para el presente de las familias recuperantes, así como de una perspectiva de futuro, al reivindicar la conformación de la comunidad como el resultado de esfuerzos familiares.

De igual manera, representa la esperanza de que su historia lleve inspiración a familias sin tierra para que se organicen y luchen, y que contribuyan al sostenimiento de la moral de resistencias similares que ya se encuentren en marcha. Esto al reconocer que forman parte de los grandes sectores del campesinado con quienes comparten condiciones similares de exclusión.

Finalmente, esta relación entre la memoria colectiva y el proceso de recuperación de tierra pasa por un esfuerzo por conservar y disfrutar su modo de vida campesino, lo cual demanda no solo recuperar la memoria, sino que este tenga un territorio donde arraigarse para poder ser reproducido, donde sus conocimientos y sus prácticas puedan ser aprendidas como parte de una cultura, pero también como estrategias de sobrevivencia para las nuevas generaciones.

\section{Identidades en E1 Triunfo}

Este análisis se hace sobre sujetos que se construyen en su devenir. Como se dijo antes, no se trata de analizar 
la identidad de la comunidad como una estructura monolítica y homogénea, en cambio, se exploran las identidades que se han construido en relación al proceso de recuperación de tierra, articuladas por medio de la participación en la lucha, a la vez que, por biografías similares que se encuentran en diálogo en sus encuentros y diferencias, teniendo múltiples puntos de contacto históricos, geográficos, socioeconómicos, culturales y prácticos.

En este sentido, las múltiples formas de identificación que conviven y se reconstruyen en esta comunidad reflejan procesos subjetivos dinámicos en constante transformación (Montero, 2004), en los cuales las familias recuperantes se autodefinen desde un territorio constituido a partir de la organización comunitaria, pero también a partir de su cotidianidad, la cual pasa por la producción de subsistencia y otras formas de sobrevivencia.

\section{Identificación con el modo de vida campesino}

A lo largo de este proceso de lucha por la tierra, que se ha visto marcado por la represión, la discriminación y la ineficacia del Estado para garantizar la protección de sus derechos, un elemento que destaca en la narrativa que sobre sí mismas hacen las familias recuperantes es la figura del "somos muy pobres", lo que da cuenta de un reconocimiento de su condición de exclusión, pero también como parte estructural de la figura de "víctima".

Esta última aparece en gran medida porque lo han sido de múltiples maneras, por ejemplo, a causa de la guerra de civil en Nicaragua, el despojo de sus tierras, la explotación de las empresas agroindustriales, las estafas de los intermediarios, la represión de la Fuerza Pública y la seguridad privada, y en general de un modelo de desarrollo capitalista excluyente.

Bajo esta línea, en El Triunfo se manifiestan de manera dinámica y contradictoria, algunas de las actitudes contenidas en tres binomios que Martín-Baró (1973) identifica como estructurales del campesinado. Primero, desacogimiento - auto devaluación, en el que producto de la exclusión socioeconómica y política, estas familias se suelen identificar a sí mismas como víctimas de un modelo desarrollo que busca por todos los medios suprimir sus derechos y crear en ellas una sensación de impotencia ante esa condición.

Segundo, cierre-fatalismo, estrechamente relacionado con las condiciones de exclusión, en la que la falta de oportunidades de la mayoría de las familias recuperantes para tener acceso a educación de calidad, en especial de los miembros adultos, se traduce en la prevalencia de una estructura de pensamiento mágico, enlazado a una débil conciencia histórica, y en el conformismo ante ciertas circunstancias.

Tercero, opresión-individualismo, el cual resulta de la falta de autonomía que esta comunidad tiene para colocar sus productos en el mercado, ya que no cuentan con una estrategia comunitaria que permita asumir esa necesidad de manera colectiva. Las reglas del mercado se imponen, de modo que cada familia de manera individual debe encontrar una solución, provocando dependencia de lo impuesto por el modelo de desarrollo económico, teniendo que integrarse al mismo en un proceso de enajenación.

Sin embargo, estas actitudes no se expresan de manera estática en las familias recuperantes. En este sentido, Victoria y Juan, mencionan como su condición de pobreza ha determinado la forma en la que han debido afrontar la vida y como la esperanza de tener tierra propia representa una alternativa para superar esa condición o al menos para sobrellevarla con mejores oportunidades:

-El objetivo fue haberse venido para acá porque, bueno como uno es pobre verdad, si van regalar estas tierras, diay uno pobre tiene que ver cómo hace, diay entonces dije yo si ahí la tierra es regalada como dicen entonces yo me vine para esta parte-. (Mujer adulta/nicaragüense/ marzo 2015). 
- ¡Yo soy campesino 100\%!, pero por la problemática de ser uno pobre, nunca ha podido tener una tierrita, nunca pude tener una facilidad para trabajar la tierra, a pesar de que soy del campo pero nunca tuvimos nada, andando de un lado para otro-. (Hombre adulto/nicaragüense/junio 2015).

En estos relatos, aparecen otras identificaciones que van más allá de ser pobres y víctimas, ya que el autonombrarse como "campesinos", expresa la autodefinición como parte de una cultura ligada al trabajo familiar en el campo, lo cual dota de otros sentidos las formas en que se configuraran las imágenes sociales de estas familias en torno al proceso de recuperación de la tierra.

Algunas de las virtudes que distinguen a estas familias recuperantes son la esperanza, el aguante y el esfuerzo dirigido a transformar sus condiciones, aún a pesar de las actitudes estructurales del campesinado señaladas por Martín-Baró (1973). Estas se expresan de manera dinámica, se mantienen latentes, emergiendo ocasionalmente, por ejemplo, cristalizándose como frustración y desesperanza ante situaciones críticas vividas en la comunidad, como la represión, la negligencia estatal y/o la dependencia a la economía capitalista.

Se trata de un grupo de sujetos que deben convivir y superar diariamente el desafío material y subjetivo que implica su condición de exclusión, lo cual pasa por emprender acciones que hagan lazo con su realidad en cuanto la posibilidad de transformarla. Como plantea el autor si bien los tres binomios son características negativas que están presentes en este grupo social "esto no quita que el campesino pueda comprometerse en una tarea, cuando ese compromiso respete su cuadro de referencia o cuando la realidad ante la que ha de comprometerse pueda ser percibida como una realidad suya y para él” (Martín-Baró, 1973, p. 488).

El poner el foco sobre la manera en que algunos de los individuos de estas familias se autonombran, permite comprender los lugares desde donde llevan adelantes sus reivindicaciones políticas y la exigencia de sus derechos. Para esto es necesario trabajar con las pertenencias que se han construido en ese espacio comunitario, lo que "implica partir desde abajo, desde las prácticas de los identificados o representados, para comprender cómo se apropian, rechazan o aceptan estas identificaciones y estas imágenes" (Avanza y Laferté, 2017, p. 202).

En relación a esto, durante el desarrollo del trabajo con la comunidad, quedó de manifiesto por medio de las entrevistas, las actividades grupales y las conversaciones informales, que en las familias recuperantes prevalece el sentido de pertenencia a la cultura campesina, la cual se expresa en términos concretos en el manejo de conocimientos y prácticas propias de la agricultura familiar para la subsistencia. En este sentido, Ernesto comparte su autoconcepción como campesino y las distinciones que a su criterio deben hacerse:

-Yo me denomino campesino agricultor, porque una cosa es que uno sea campesino empleado, agricultor es el que tiene la profesión de agricultura, toda la vida lo he sido, porque mi papá lo era. Saqué mi sexto grado en una escuela rural y mi papá me dijo -te vas para San Carlos a sacar el colegio. Y yo no quise ir, le dije que quería dos rulas y una lija, y me fui a sembrar solo, porque era muchacho, mi papá me motivaba mucho. Toda la vida me ha gustado el campo, comer fresquito, el plátano, el huevo fresquito, la tortillita de maíz, ordeñar y engordar chanchos. Todo lo que se come afuera es del campo, la verdurita, la frutita, todo, todo, todo, la leche, porque la vaca está en el campo-(Hombre adulto/nicaragüense/febrero 2015).

El relato anterior, pone en evidencia una concepción amplia del campesinado, que se entiende asociado al trabajo directo de la tierra, en la que se incluye la categoría de peón agrícola, pero en la que se reivindica una distinción por las características de esa relación con la tierra, con la cual se posiciona la figura del campesino agricultor. Esta imagen, va más allá de la producción agropecuaria por cuenta propia, involucrando una identificación atravesada por el disfrute de la vida en el campo y el sentido de concebirse necesarios para la sociedad.

En la misma línea, pero en un sentido distinto, para el caso de esta comunidad otra categoría a través de la cual se construye la identificación como campesinos es por contraposición con lo urbano. El contraste entre 
esos dos modos de vida determinados por una amplia multidimensionalidad (geográfica, económica, política, social y cultural), permiten marcar con más claridad los atributos desde donde definen su sentido de pertenencia y su proceso de identificación:

-Yo me siento alegre aquí en el campo, porque nunca me ha gustado la ciudad- (Luz/mujer adulta/nicaragüense/julio 2014).

-Porque todo el tiempo que viví en la ciudad no fue vida para mí, una persona que ha vivido su vida en el campo no se acostumbra a la ciudad, a la edad que tengo yo todavía no me he acostumbrado a la ciudad, a pesar de que allá trabajé de lo más bien, trabajé 8 años en la arrocera de Costa Rica, en seguridad, ahí en una casetilla, no me asoleaba, no me mojaba, es decir que ahí se la pasaba uno. Yo vivía ahí en Santa Rita, en el "Infiernillo", ahí tuve una casa, pero aun así la vida del campo es más dura, aquí hay zancudos, bueno ustedes ya saben cómo se sufre aquí, pero me la llevo más tranquilo aquí que allá. Es que uno está acostumbrado a esto, y algo a lo que no se acostumbra, le cuesta dejar las costumbres-(Juan/hombre adulto/ nicaragüense/junio 2015).

-No me gusta la ciudad, no sé, uno vive como preso, no puede salir, solo hacer mandados, pero sino ahí está en la casa, todo se compra, las verduras, en cambio en una finca no compra nada, porque si quiere una gallina la agarró y hago la sopa. Yo les digo a mis hermanas que ni loca me voy a la ciudad. Yo sé ordeñar, andar a caballo, mi anhelo es que si tengo parcela comprar una vaquita, para ordeñar, tener leche, sino diay- (Victoria/mujer adulta/nicaragüense/marzo 2015).

En estos relatos, se evidencia que la pertenencia campesina de las familias recuperantes se identifica con una imagen social vinculada al campo, con características definidas, sustentada en valores, creencias, conocimientos, prácticas y costumbres tradicionales tal y como lo indica Robert (1996) citado en Cordero, Dobles y Pérez (1996), que tiene arraigo en lo rural, la cual intenta situarse fuera de las formas de producción y relaciones de trabajo propias del modelo agroindustrial que se definen como enajenantes.

\section{E1 símbolo "tierra"}

Ante este panorama, la tierra destaca como una constante articuladora de la biografía, las identidades construidas, el deseo, la sobrevivencia y la sostenibilidad de la lucha figura como la motivación principal por la cual las familias de El Triunfo se mantienen unidas, entendida como propiedad privada y como una manera de disfrutar su cultura campesina, para heredar ambos elementos, material e inmaterial a sus descendientes.

Esta identificación que pasa por la materia "tierra" además de simbolizar un recurso primario para la reproducción de la vida, es un símbolo sobre el cual se constituye en gran medida la pertenencia de las familias recuperantes, en especial de quienes han vivido y trabajado en la finca desde el inicio de la lucha. En el siguiente cuadro (cuadro 2), se muestran algunos de los significados que tiene el símbolo "tierra": 
CUADRO 2.

Significados atribuidos al símbolo "tierra"

\section{Tener lo propio}

Trabajar de manera autónoma

Evitar la migración rural-urbana por motivos laborales

Sobrevivir de la agricultura familiar

Fuente de vida para el presente

Fuente de vida para los demás

Fuente: Elaboración propia a partir de actividad grupal, Agosto 2014.

Como se observa, estos significados atraviesan dimensiones socioeconómicas, pero también subjetivas, en la que se concibe no simplemente como un recurso que puede ser explotado para generar mercancías, sino principalmente como una forma de generar autonomía. De esta manera, el elemento material (tierra), se convierte en el símbolo constitutivo de su identificación como familias campesinas recuperantes de tierra: -somos los que labramos la tierra, somos los que vivimos de labores cotidianas, somos los que vivimos de labores cotidianas de la tierra- (Rebelde/hombre adulto/nicaragüense/enero 2015).

Lo anterior concuerda con la idea de que aunque la "tierra" existe como materia prima, esta es sobre todo un símbolo para un individuo o para un grupo, y que su significado no es absoluto, sino que depende de quien lo interpreta y lo simboliza (Pavón, 2012). Las distintas simbolizaciones responden a una historicidad determinada, ya que para quien proviene de la ciudad, la tierra no simboliza lo mismo que para alguien socializado en el campo, no obstante, dentro de la territorialidad rural, este símbolo tiene significados distintos para un terrateniente o una empresa agroindustrial, que para las familias de esta comunidad autodefinida como campesina.

\section{El Triunfo como reivindicación ante la noción de precarista/terrorista}

En lo anterior, se evidenció la centralidad que la pertenencia campesina de las familias recuperantes tiene en relación con el proceso de lucha por la tierra, ahora bien, este proceso ha dado como resultado otra imagen social central, específica a la construcción colectiva de la comunidad, se expresa principalmente en el nombre con que se denominó a la comunidad, El Triunfo, siendo que el momento en que se nombró así no puede ser situado en un punto exacto de su historia, ya que el tiempo se ha encargado de legitimar y reconocer años de lucha y de resistencia, en los que se han superado diferentes formas de violencia, tanto del arrendatario, como del Estado: malas condiciones de vida y actitudes hostiles de algunas comunidades cercanas, contextualizan la elección de ese nombre, pero en un sentido más profundo significa una reparación de su propia dignidad y la legitimación de su condición de grupo organizado que se encuentra recuperando la tierra para sobrevivir. Desde que este grupo de familias comenzó su proceso de recuperación de tierra, han sido calificadas de múltiples maneras negativas, buscando denigrar su condición humana, deshumanizarlas y etiquetarlas como enemigas de la sociedad. Al respecto, Juan narra el trato recibido por las comunidades aledañas:

-El que tenemos de vecino más cercano, nos trataba de precaristas, de ladrones de tierras ajenas. Él hablaba mucho, como él tiene su ganado ahí libre, tranquilo, tenía miedo que los precaristas le comieran las vacas, pero gracias a Dios que no, nadie actuó así- (hombre adulto/nicaragüense/junio 2015).

Durante los talleres realizados, las personas participantes también compartieron sus vivencias en este sentido, señalando que fueron tratadas de "lacras" y "precaristas". Sumado a estos calificativos, se añadió el de 
"terroristas", ya que, en un audio donde en apariencia se escucha a un subteniente de la Fuerza Pública, capacitando a guardias de seguridad privada al servicio del arrendatario de la finca, este decía: "es la palabra de ustedes contra un aterro de ... terroristas, porque eso es lo que son, un aterro de ... si le van a pegar un balazo a un ... traten de darle en la cabeza para que no se pueda mover, para que haya escena del crimen y ustedes puedan demostrar que están evadiendo una agresión” (Era Verde, 2012).

Sobre esta categoría en particular, Calveiro (2006) hace un análisis estructural de como el "terrorista" se convierte en una amenaza totalizante, en cuanto es todo lo que se salga del orden establecido:

La definición de peligrosidad extrema del terrorista es la justificación para un tratamiento preventivo al margen de cualquier protección legal. Así, un terrorista no es aquel que cometió un acto más o menos tipificable en esa dirección, sino cualquiera a quien se considere potencialmente capaz de cometerlo. El terrorista se construye como una categoría difusa, en la que puede incluirse a muchos Otros étnicos, políticos, raciales; en este sentido, se podría decir que encarna al Otro en el mundo global. (p. 372)

Estos planteamientos, apuntan hacia el hecho de que se crean maneras de deshumanizar al Otro, que en el caso de esta comunidad, son las familias que buscan las maneras de transformar sus condiciones de vida y de disfrutar la cultura con la que se sienten identificadas, quienes han recurrido a una acción ilegal a falta de vías institucionales efectivas.

La colocación de estas familias en la posición de "ladronas" y de "terroristas", por lo tanto de enemigas sociales, sucede precisamente por la relación de poder desventajosa que tiene esta comunidad frente a quienes representan y benefician esos discursos hostiles. En este caso, el discurso deshumanizante ha operado para favorecer los intereses del arrendatario.

Ahora bien, aunque este discurso aún permanece latente, en la memoria colectiva de las familias de la comunidad prevalece el autoreconocimiento como "triunfadoras". La imagen que sobre sí mismas tienen ha cambiado respecto al pasado, esto se relaciona con el reconocimiento social de las múltiples formas de violencia que han afrontado y con haber logrado que el Inder iniciara con el proceso formal de asignación de tierras.

Lo anterior, también ha tenido una incidencia sobre la forma como algunas personas participantes recuerdan la lucha en sus momentos más críticos, en los que destaca una exaltación de su valentía ante las amenazas. Esto se logra entender en el siguiente fragmento relatado por Ernesto:

-Como era una decisión ya tomada verdad, de vida o muerte, no nos íbamos a ir, no nos íbamos a echar para atrás porque mucha gente dice que los más valientes de cualquier sociedad son los campesinos y si es verdad, porque yo lo vi, todos los disparos cayendo al suelo y nosotros pa'delante-. (Hombre adulto/nicaragüense/febrero 2015)

La intervención del Inder ha tenido un efecto positivo, por las razones obvias de brindar el acceso a la tierra para estas familias, pero, también porque ha legitimado su lucha como justa ante las y los que alguna vez las vieron como enemigas de la sociedad, evidenciando que el encontrarse en esa condición no es una simple elección sino una estrategia de sobrevivencia ante la falta de otras alternativas para transformar sus condiciones de vida (Cordero, 1998).

Las múltiples dificultades que las familias recuperantes han afrontado a lo largo de esta lucha, eran entendidas como temporales, sin embargo, esa supuesta provisionalidad se ha extendido por mucho más tiempo de lo pensado. Algunas personas, muestran en sus relatos la forma en que esta situación se ha vivenciado: 
-Ha sido muy difícil todo, nosotros estábamos acostumbrados a donde estábamos más mejor, ahora estamos más mal porque diay beber agua contaminada, es un agua muy cochina. Nos ha costado a muchos, vamos adelante, avanzando porque tal vez nos dan donde vivir, porque nunca hemos tenido donde vivir, casa propia ¿nosotros? ¡Nunca!-. (Mujer adulta/nicaragüense/enero 2015).

-Vieras que duro fue al principio, eso de estar uno acostumbrado que por todo lado tiene la luz encendida, no anda en lo oscuro, pero cuando viene aquí uno a alumbrarse con una canfinera o una candelita, no me hallaba con eso de la luz. Otro asunto incómodo que lo sentía es cuando uno se va a bañar, el barro allí donde pone los pies, ahí es un cambio terrible, uno no se siente bien, todo eso es feo cuando uno no está acostumbrado a eso, pero aun así uno superó eso. Porque uno no se acostumbra, lo hace porque tiene que hacerlo, pero no es nada bonito-. (Hombre adulto/ nicaragüense/junio 2015).

-Yo me he ido acostumbrando por luchas en Nicaragua. Yo no quisiera dejar aquí porque uno no sabe más nada que lo que tiene y ha visto aquí. Cuando salí de mi casa donde tenía buena cama, cocina, paredes, a venirme aquí con poca ropa a una champa y a cocinar frijoles y en los mismos frijoles la yuca. Y no hay luz, agua, yo le digo a mi familia, acostúmbrense a los momentos difíciles, porque podemos llegar a vivir peor-. (Hombre adulto/nicaragüense/febrero 2015).

Como se muestra en estas narraciones, recuperar una tierra, es una decisión con diversas motivaciones y presiones estructurales, comparable con la decisión de migrar. Ante las reducidas opciones para mejorar sus condiciones de vida, se opta por tomar un riesgo y asumir condiciones a las que no se está acostumbrado, como una vía a largo plazo para alcanzar la estabilidad social y económica. En ambas condiciones (recuperante y migrante) media la cuestión de la ilegalidad, lo cual alimenta también la configuración de la imagen del enemigo.

El reconocimiento como una comunidad "triunfadora", pasa también por el reconocimiento social de la re-territorialización de ese espacio, que ha dejado de ser utilizado para la producción a gran escala, para transformarse en un territorio donde conviven muchas familias que trabajan la producción agropecuaria; esto queda mejor ilustrado en una frase dicha por una de las personas participantes durante una actividad grupal: -ahora mucha gente quiere participar, mucha gente en los buses comenta que bien trabajamos esta finca- (actividad grupal, mayo 2015).

Este cambio subjetivo a nivel de la comunidad, implica además la superación de la vergüenza y la reivindicación política como familias luchadoras por un derecho justo, ya que abundan las historias, especialmente en conversaciones informales, que narran que al inicio era común el sentimiento de vergüenza por participar en esta lucha, por ejemplo, al estar a la orilla de la calle esperando para volver a ingresar a la finca después de los desalojos.

Al preguntar ¿qué pensarían si fueran otras familias las que se encuentran en su situación?, las respuestas fueron variadas, girando en torno a la posición de víctimas y no de enemigas. Es decir, se trata de un ejercicio de auto reconocimiento, en donde se pone de manifiesto su propia construcción de lo que han vivenciado como comunidad, identificándose con ese otro imaginario en el que se reflejan, quedando claro con el siguiente fragmento: -solo pobre con pobre se entienden, el que tiene plata pensaría que somos unos sin vergüenzas- (actividad grupal, mayo 2015).

\section{Reflexiones finales}

De este modo, se sostiene que en El Triunfo es una comunidad de identidades construidas, sustentadas en biografías comunes o cercanas, con condiciones de vida excluyentes, con procesos migratorios y sentido de pertenencia a la cultura campesina; donde el proceso de recuperación de tierra ha sido el nudo articulador. El Triunfo existe como un territorio recuperado, pero es también un símbolo que se resignifica desde la propia vivencia, en tanto, más que un recurso primario, representa la posibilidad de satisfacer el deseo de vivir 
de la agricultura familiar. Representa un proceso de humanización en la reivindicación a estas familias como "triunfadoras" ante los discursos hostiles que las colocan como "enemigas". Reconociéndose, como parte de un sector más amplio del campesinado sin tierra, esperando aportar a sus procesos de resistencia.

De manera que, el proceso de recuperación de tierra se expresa en la conformación de una comunidad a partir de las interrelaciones familiares, en torno a las necesidades, acciones, memorias e imágenes compartidas. Dicho proceso es entendido no como algo terminado, sino como un proceso en constante construcción, un devenir que transmite sentido a la realidad comunitaria, en el que participan de forma central la recuperación de la memoria colectiva, en estrecha relación con la autodefinición como familias campesinas a partir de la "tierra" material y simbólica, pasando por una perspectiva de futuro basada en la esperanza.

\section{Referencias Bibliográficas}

Avanza, M. y Laferté, G. (2017). ¿'Trascender la "construcción de identidades"? Identificación, imagen social, pertenencia, Revista Colombina de Antropología, 53(1), 187-212.

Calveiro, P. (2006). Los usos políticos de la memoria. En Sujetos sociales y nuevas formas de protesta en la bistoria reciente de América Latina (359-382). Buenos Aires, Argentina: CLACSO, Consejo Latinoamericano de Ciencias Sociales.

Cordero, T. (1998). Experiencia psicosocial de Bahía Pavones de Golfito. Actualidades en Psicología, 14(98), 1-53.

Era Verde. (2012). Represión en Medio Queso: los campesinos ocupan tierra. [Entrevista]. De Canal UCR.

Jelin, E. (2014). Memoria y democracia. Una relación incierta. Revista Mexicana de Ciencias Politicas y Sociales, 59(221), 225-242.

Martín-Baró, I. (1973). Psicología del campesino salvadoreño. Estudios Centroamericanos, ECA, 28(297298), 476-495.

Montero, M. (2004). Introducción a la psicología comunitaria. Desarrollo, conceptos y procesos. Buenos Aires, Argentina: Editorial Paidós.

Pavón, D. (2012). El manzano revolucionario de Gustave Flaubert y los ocho materialismos de Jacques Lacan. Affectio Societatis, 9(17), 1-20.

Robert, J. (1996). El campesino costarricense: carácter social y modernización. (Una exploración psicosocial de las tendencias profundas de la subjetividad en un grupo). En: Cordero, T, Dobles, I. y Pérez, R. (comp.), Dominación Social y Subjetividad. Contribuciones de la Psicología Social. San José, Costa Rica: Editorial Universidad de Costa Rica. 